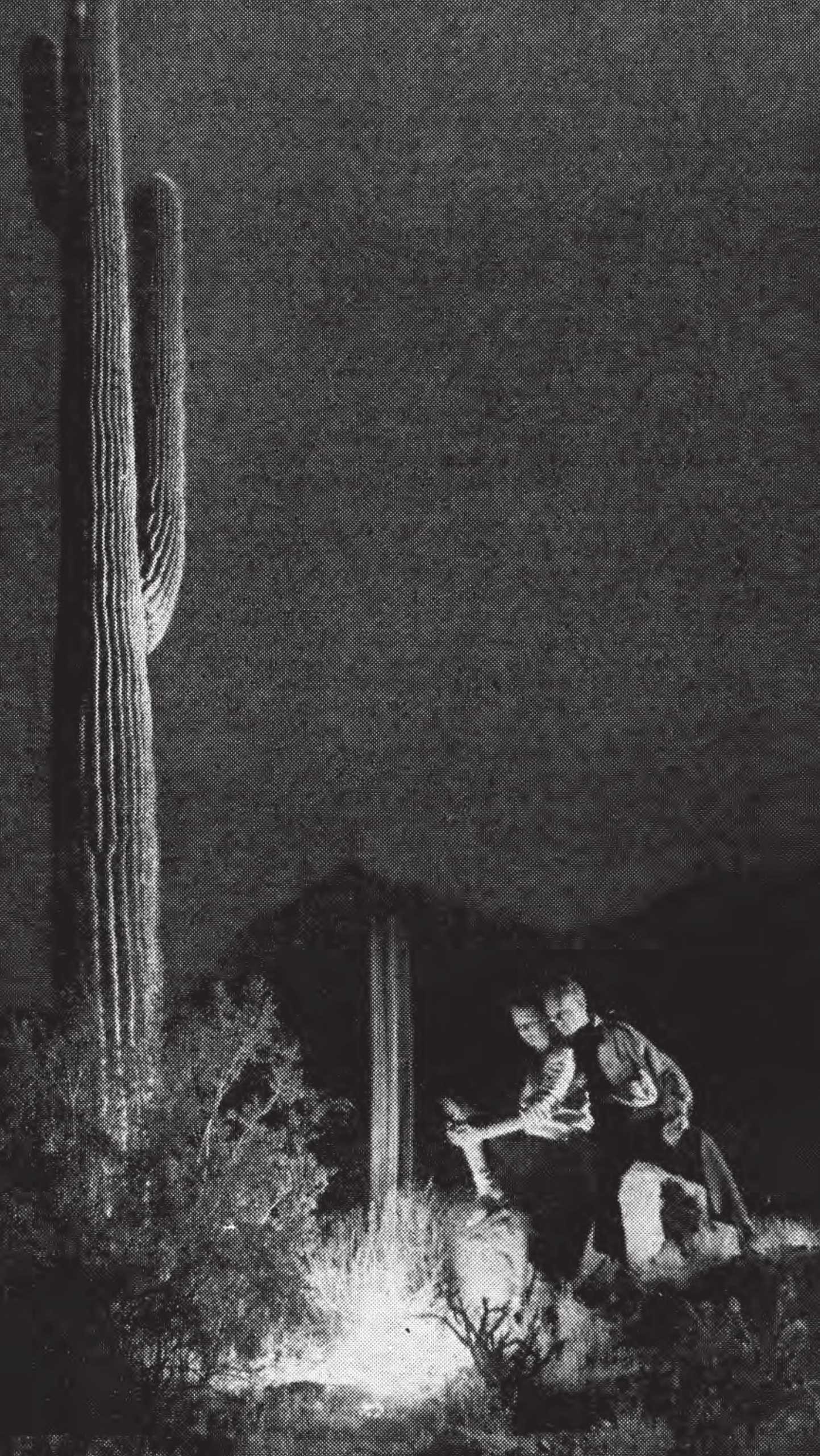




\title{
CRÍTICA E CONTRADIÇÃO: QUAL HERANÇA MARX̉ISTA?
}

\author{
RÚRION MELO
}

\section{RESUMO}

Em Trabalho e reflexão e Certa herança marxista a reflexão de José Arthur Giannotti sobre a racionalidade do capitalismo contemporâneo o força a avançar em relação às categorias elaboradas originalmente por Marx. $\mathrm{O}$ artigo avalia criticamente as implicações da nova caracterização da dialética da sociabilidade capitalista oferecida por Giannotti para a sobrevida de uma herança marxista que procura manter a crítica imanente de Marx à positividade do capital.

PALAVRAS-CHAVE:Marxismo; gênese lógica; genes histórica; capitalismo contemporâneo.

\section{ABSTRACT}

In his book Trabalho e reflexão [Labor and reflexivity], José Arthur Giannotti's considerations about late capitalist rationality forces him to develop some of Marx's original concepts. This article offers a critical reading of the consequences of a renewd understanding of the dialectics of capitalist sociability elaborated by Giannotti for the survival of a Marxist critical legacy that aims at refreshing Marx's immanent critique of capitalism.

KEYWORDS: Marxism; logical genesis; historical genesis; late capitalism.

[1] Cf. Giannotti, José Arthur. Origens da dialética do trabalho. São Paulo: Difusão Europeia do Livro, 1966.
Em sua apresentação de Origens da dialética do trabalho ${ }^{1}$, Gérard Lebrun chama atenção para um aspecto crucial, porém sujeito a incompreensões, da interpretação encontrada nesse estudo: não vemos na leitura de José Arthur Giannotti sobre Karl Marx as recorrentes palavras de ordem e profecias pregadas pelo marxismo. Mas não só isso. Vemos ali sobretudo um modo particular de se colocar criticamente diante de uma apropriação de Marx impregnada de traços religiosos que se dedica a "estudar Marx do modo pelo qual Gueroult comenta Descartes". Embora alguns tivessem concluído que essa interpretação de Marx seria neutra em relação aos desdobramentos práticos e políticos que sua teoria suscita, essa conclusão não parece se aplicar sem mais aos estudos de Giannotti. A tentativa de pensar a obra de Marx "pela raiz" 2 , sem, contudo, acreditar que seu pensamento "possa existir em si, independentemente dos pensamentos que o 
pensam"3, pressupõe um diagnóstico sobre o capitalismo atual, um espírito crítico diante das práticas sociais e políticas institucionalizadas pelo marxismo e um esforço de compreensão da realidade brasileira. Mesmo em seu mais recente livro defrontamos novamente com a insistência em "voltar à leitura cuidadosa dos textos originais [...] para não perder de vista certas escolhas teóricas que Marx fez durante a montagem de sua obra" 4 . Não entendemos essa atitude teórica de Giannotti, presente no conjunto de seus escritos filosóficos, se a interpretamos como se estivesse limitada a implicações metodológicas "acríticas". Ao filósofo não cabe somente produzir discursos de método. Tomamos sua insistência como uma recepção interessada e que teria de ser questionada, portanto, também tendo em vista a história dos efeitos dos problemas filosóficos legados por Marx.

No prefácio de Origens da dialética do trabalho, Giannotti sugere que "antes de postular o marxismo como a filosofia viva de nosso tempo e sair à procura da legitimação teórica de sua prática, cumpre estabelecer com toda precisão como Marx, no exercício de sua atividade científica, encaminhou o problema" 5 . Essa precisão não será empregada apenas contra as leituras menos rigorosas do marxismo. Lembremos, por exemplo, que a partir da demonstração de uma incompatibilidade existente entre os textos de Marx e a interpretação de Louis Althusser, Giannotti também denunciou em 1968 a aproximação feita por Althusser entre a filosofia marxista e a tradição epistemológica do positivismo francês ${ }^{6}$. A disputa no plano da recepção em torno de uma leitura rigorosa da obra de Marx teve lugar, assim, no interior da tradição universitária. Acontece que uma crítica aparentemente preocupada em apontar os prejuízos de uma interpretação livre e "inverificável" dos textos de Marx recoloca problemas substantivos para a compreensão do presente, reduzida pela abordagem positivista: entender a história da produção capitalista narrada no Capital é considerar todos os passos necessários da posição do capital, atentar para a gênese objetiva de suas formas e, sobretudo, mostrar como ocorre efetivamente o processo de constituição categorial. Buscar uma compatibilidade conceitual mais adequada do texto, neste caso, não seria um meio de indagar de fato sobre o conhecimento dos fenômenos sociais possibilitado pela dialética marxista? Se soubéssemos como o problema foi encaminhado por Marx, sugere Giannotti, talvez pudéssemos compreender igualmente de que modo leitura e diagnóstico se condensam na recepção dos textos.

Os estudos de Giannotti específicos sobre Marx abrangem uma quantidade considerável de textos e temas particularmente complexos. Acompanhar seu percurso não é tarefa fácil. No entanto, pegaremos um atalho que nos permitirá chegar ao que entendemos ser a contribuição mais original de sua interpretação: a distinção proposta
[3] Giannotti, J. A. Certa herança marxista. São Paulo: Companhia das Letras, 2000, p. 12.

[4] Giannotti,J.A. Lições de filosofia primeira. São Paulo: Companhia das Letras, 2011, p. 15.

[5] Giannotti, J.A. Origens da dialética do trabalho, op. cit., p. 10.

[6] Cf. Giannotti, J. A. "Contra Althusser". In: Exercícios de filosofia. São Paulo: Vozes, 1980, pp. 85-102. 
entre gênese lógica e gênese histórica, bem como a análise sobre a contradição. No que diz respeito a essas questões, não nos interessa apenas entender a perspectiva do historiador da filosofia, mas também como tais questões são retomadas por Giannotti e reconfiguradas em seus próprios termos a fim de permitir também pensar a contemporaneidade. Por isso nossa opção de passar dos estudos de Origens da dialética do trabalho para as análises contidas em Trabalho e reflexão e Certa herança marxista: nesses textos posteriores é que sua reflexão sobre a racionalidade do capitalismo contemporâneo forçaria Giannotti a avançar em relação às categorias oferecidas por Marx. Contudo, quais seriam as implicações dessa nova caracterização da dialética da sociabilidade capitalista para a sobrevida de uma herança marxista que procura manter a crítica imanente de Marx à positividade do capital?

Origens da dialética do trabalho é o primeiro grande passo de Giannotti em seu longo acerto de contas com a dialética. A história apresentada é a da evolução das próprias ideias de Marx. O livro considera a dialética desde suas primeiras formulações materialistas a partir de Ludwig Feuerbach e das aparentemente agudas análises do jovem Marx, saindo em busca, no entanto, da "gênese de sua ilusão". Pressupondo uma "radical oposição epistemológica" entre os textos de juventude e os da maturidade de Marx, Giannotti não se limita a recontar aquela gênese, mas se preocupa ainda em avaliá-la criticamente, ao mostrar que a dialética, estruturada no valor e no trabalho, passou a constituir uma substância social somente nos textos da maturidade. Dialética com densidade ontológica, a crítica madura da economia política opera com "universais concretos" em que as categorias se exprimem na própria realidade, ou seja, no sistema produtivo capitalista. E é a confluência necessária entre lógica e ontologia que interessa a Giannotti: a dialética do trabalho permite que compreendamos o sentido da ação social e a racionalidade que lhe é imanente sem precisarmos recorrer às abstrações hegelianas.

Entretanto, nos textos do jovem Marx (em especial, nos seus Manuscritos econômico-filosóficos de 1844), o trabalho não é determinado pelo modo de produção capitalista. É verdade que nos Manuscritos encontramos, na esteira de Feuerbach, a passagem do idealismo hegeliano para uma primeira versão da dialética materialista. Para escapar de formulações abstratas, fundadas em desdobramentos conceituais, o "jovem" Marx articula explicações que, ao se apoiarem na categoria do trabalho, oferecem processos vinculados não a operações especulativas, mas a atividades materiais. Porém, a articulação entre trabalho, propriedade, sociedade civil e alienação, central para sua primeira crítica da economia política, ainda não é constituída pelas relações econômicas que se objetivam no sistema capitalista. 
Giannotti denuncia essa limitação ao mostrar que tal articulação acaba por se situarfora da economia, algo que mesmo alguns dos melhores autores do marxismo deixaram de salientar. As análises econômicas dos Manuscritos são empreendidas de um ponto de vista filosófico que também permanece abstrato, procedimento metodológico que começará a se inverter somente na Ideologia alemã, redigida entre 1845 e 1846, e que encontrará uma solução adequada nas décadas de 1850 e 1860. Nos primeiros textos, com a filosofia de Feuerbach ainda muito presente, o fundamento da crítica dependia de uma "antropologia fundante" 7 a partir da qual o jovem Marx analisava o trabalho. Nos textos da maturidade, no entanto, a crítica da economia política edifica suas bases sobre a dialética específica do modo de produção capitalista. Não podemos mais "pensar o marxismo como filosofia viva" sem que atentemos para essa urgente disparidade epistemológica que lançaluz sobre a "falsa dialética" que deu origem aos enganos da primeira crítica da economia política. Esse déficit concernente à economia política impediria o jovem Marx de elaborar uma apresentação adequada dos processos efetivos pelos quais se produz o sentido da ação social.

Há nos Manuscritos uma primeira indagação de teor crítico quando, com o conceito de trabalho, Marx procura evidenciar a gênese explicativa do fato da propriedade privada. A economia política assumia a propriedade privada como um fato sem nos explicar sua gênese. Marx, por sua vez, entende a propriedade privada como expressão material de determinado tipo de trabalho - o trabalho alienado. No entanto, a alienação é concebida de acordo com a vinculação entre propriedade privada e um tipo de propriedade verdadeiramente humana. O conceito de trabalho pressupõe assim não apenas seu referencial econômico, atrelado à forma histórica específica do trabalho assalariado, mas principalmente uma noção filosófica de objetivação: uma atividade essencial e universal do homem, constitutiva da totalidade de sua vida produtiva, isto é, de sua atividade vital como ser genérico. O trabalho é concebido aqui como uma atividade de autorrealização humana, de modo a combinar a expressão da vida produtiva com a objetivação da vida genérica do homem ${ }^{8}$. Essa noção filosófica, no entanto, não é pensada ainda como uma categoria verdadeiramente histórica, pois está atrelada a uma forma de sociabilidade primitiva e passa a funcionar como o núcleo dessa compreensão antropológica que implica uma homologia entre todas as atividades humanas.

O desvirtuamento dessa autorrealização humana é identificado por Marx ao analisar a atividade dos trabalhadores sob o jugo do capital. O resultado do trabalho assalariado se condensa na propriedade privada, no produto alienado de sua relação verdadeiramente humana e social. Nesse caso, o trabalhador não se reconhece em seu produto, é separado de sua coletividade, passa a produzir heteronomamente
[7] Giannotti, J.A. Origens da dialética do trabalho, op. cit., p. 183.

[8] Cf. Marx, K. “Ökonomisch-philosophische Manuskripte (1844)". In:Marx-Engels Werke. t. 4o. Berlim: Dietz Verlag, 1990, p. 517. 
[9] Cf. ibidem, pp. 510 ss.

[10] Cf. ibidem, pp. 137-38.

[11] Ibidem, p. 110. sem que seu trabalho manifeste sua essência como ser genérico, perde todo o sentido social de sua ação e se transforma em um não homem, em proletariado'. Desse modo, não éapenas o produto que, ao resultar do trabalho alienado, se separa de seu produtor como uma coisa absolutamente estranha. Também nessa atividade alienada o homem se aliena de seu próprio ser genérico e se torna independente na medida em que se abstrai do contexto originário e totalizante do trabalho. Seo objeto do trabalho não pode mais ser compreendido como objetivação do ser genérico, então a atividade do trabalhador no capitalismo se limita a uma operação isolada de satisfação da existência individual do homem. A alienação perpassa esses três momentos: o do caráter alienado do produto do trabalho, o da ação de produzire o das relações vigentes entre o indivíduo e a espécie ${ }^{10}$.

Mesmo as mais fascinantes formulações encontradas nos textos do jovem Marx oferecem, como sugere Giannotti, uma solução enganosa para a dialética materialista. O núcleo normativo da crítica de Marx nos Manuscritos, ainda que atravesse os conceitos da economia política, pressupõe antes uma universalidade já constituída do homem que a realidade capitalista põe a perder: o trabalho alienado e a propriedade privada rompem aquela totalidade originária do ser genérico. Se for assim, podemos falar que há no jovem Marx uma crítica da economia política? Certamente não uma crítica imanente. Partindo da interpretação dos procedimentos metodológicos utilizados nos Manuscritos, Giannotti torna claros a particularidade e os limites da crítica apresentada nos textos de juventude: naquele período a objetividade atribuída por Marx à realidade econômica nos permite compreendê-la apenas em sua expressão "negativa", ou seja, uma objetividade que nega uma sociabilidade primitiva. "A realidade econômica", comenta Giannotti, "não possui, desse modo, valor em si mesma, não existe de per si, mas é apenas a emanação viciada da sociabilidade primitiva, de uma substância social que se situa muito além do mundo do comércio e da indústria" ${ }^{11}$. Como avaliar então uma dialética materialista que deixa de fundar o sentido das atividades sociais no interior das relações econômicas, vale dizer, do sistema capitalista? Além disso, como vislumbrar a superação da alienação senão de um ponto de vista moral abstrato, uma vez que o surgimento de uma nova forma de sociabilidade não dependeria mais das condições socioeconômicas concretas da revolução?

Não será apenas na crítica madura da economia política que encontraremos a subversão das teses filosóficas contidas nos Manuscritos. Questões econômicas e políticas fundamentais forçavam Marx a articular suas preocupações materialistas iniciais com a história. $\mathrm{O}$ "materialismo histórico" apresentado na Ideologia alemã modificará radicalmente a solução ainda feuerbachiana dos Manuscritos justamente 
porque nele encontramos "a recusa intransigente de fundar a crítica histórico-econômica numa essência genérica do homem, isto é, a negação de toda antropologia fundante"12. Momento necessário, ainda que não suficiente, de uma crítica da economia política em desenvolvimento, a versão histórico-materialista traz uma inegável novidade: com o conceito de modo de produção já não é necessário pressupor a totalidade do gênero, porque passa a ser possível trazê-la para a história e desdobrá-la nas diversas formas e sistemas de produção. "Quando se tinha a totalidade do gênero como princípio", afirma Giannotti, "era fácil ver toda a história como a realização da sociedade civil tomada como negação do princípio originário. Mas agora a totalização deve emergir da própria história e dar conta de todas as totalizações parciais"13.

O que pode conferir totalidade ao processo dialético da história sem que tenhamos de pressupor algo não constituído por seus momentos? Não sendo mais o homem universal o ponto de partida do processo dialético, Marx introduz a categoria de produção. Por um lado, existem ganhos consideráveis nesse deslocamento em direção à produção. O mais importante deles parece ser o de se preocupar com os aspectos constitutivos das estruturas sociais objetivas. Essa preocupação desloca noções abstratas como a de ser genérico para os modos de produção e seus períodos dados economicamente, da totalidade do gênero para a totalização que emerge do processo histórico, abrindo a possibilidade de pensar o trabalho não mais como a objetivação de um sujeito constituinte, mas sim a partir de processos sociais objetivamente estruturados. Por outro lado, para que possa se vincular aos diferentes modos de produção sem perder a unidade dialética dos processos históricos, a categoria de produção só pode ser concebida por Marx como uma categoria universal porque se apresentou como fruto de uma "abstração racional"14. "A categoria de produção", comenta Giannotti, "é destarte uma abstração filosófica cujos componentes são da mesma ordem das protocondições históricas da história, consiste num mero recurso do intelecto para salientar os traços comuns dos vários sistemas produtivos a fim de evitar repetições e, sobretudo, a fim de sublinhar diferenças essenciais" ${ }^{15}$.

Nesse ponto, encontramos uma das mais importantes contribuições da leitura de Marx de Giannotti. O que ainda não estava claro para Marx tanto nos Manuscritos quanto na Ideologia alemã era a distinção, apresentada nas décadas de 1850 e 1860, entre construção categorial e processo histórico, entre gênese lógica e gênese histórica: "A solução para o problema só pode advir de duas ordens de determinação: a que diz respeito à essência do fenômeno em qualquer de suas manifestações históricas e a que concerne a seu devir" ${ }^{16}$. Não é toda a história que resguarda em cada sistema produtivo uma ca-
[12] Ibidem, p. 183 .

[13] Ibidem, p. 189.

[14] Engels, F. e Marx, K. “Deutsche Ideologie". In:Marx-Engels Werke. t. 3. Berlim: Dietz Verlag, 1990, p. 69.

[15] Giannotti,J.A. Origens da dialética do trabalho, op. cit., p. 192.

[16] Ibidem, pp. 193-94. 
[17] Ibidem, p. 195.

[18] Ibidem.

[19] Essa expressão aparece em Giannotti, J. A. Certa herança marxista, op. cit., p. 314 .

[20] Cf. Althusser, L. Pour Marx. Paris: Librairie Fraçois Maspero, 1966.

[21] Cf. Löwy, Michel. A teoria da revolução no jovem Marx. Trad. Anderson Gonçalves. Petrópolis: Vozes, 2002 . tegoria geral de produção que, por um processo de abstração mental, poderia ser pensada como um traço comum a se manter nas formas produtivas mais antigas ou mais modernas. Na verdade,é a dialética específica do modo de produção capitalista - em que se definem processos de produção, distribuição e troca de mercadorias - que permite uma reconstrução genética de categorias abstratas essenciais que constituem as atividades produtivas concretas. Nesse sentido, aquela totalidade procurada nos textos anteriores, concebida ontologicamente agora a partir da gramática do capital, traduz-se como abstração e universalidade surgidas do e repostas pelo próprio funcionamento do sistema produtivo. E o que caracteriza o modo de produção capitalista, ensina Marx no Capital, não é o fato de seu sistema produtivo estar subordinado inteiramente às relações de troca de mercadorias fundadas no valor? Podemos determinar então como o sentido das ações sociais está estruturado no contexto abstrato postulado pela troca porque "somente no capitalismo o valor vem a ser a categoria dominante a propor-se como o fim último de toda atividade produtiva" ${ }^{17}$. O "modo de exposição" do Capital não precisa reproduzir, por essa razão, a gênese histórica concreta de surgimento do capitalismo para explicar o sistema capitalista. A constituição do concreto é formada assim por categorias que definem em seu todo as atividades inerentes do próprio sistema e estruturam seu modo de produção: "uma totalidade possui pressupostos de seu vir-a-ser mas tais pressupostos somente atuam no sistema se forem assumidos por ele, se forem re-postos no processo atual de sua efetuação"18. Apenas assim o modo de produção capitalista poderá ser pensado no Capital como um "lógos sem Espírito Absoluto"19.

Essa interpretação se diferencia bastante de outras leituras sobre o jovem Marx e suas comparações com a fase madura. Para Althusser, o famoso "corte epistemológico", que separa os Manuscritos do Capital, depende da distinção entre objeto real e objeto do conhecimento ${ }^{20}$. Michel Löwy, por seu turno, realça o viés político nessa comparação ao privilegiar o contato de Marx com o movimento organizado do proletariado francês e mostrar como deriva daí o conceito de autoemancipação ${ }^{21}$. Segundo a leitura de Giannotti, o distanciamento em relação a Feuerbach distingue os textos de juventude da formulação madura de Marx. Talvez seja mais frutífero ver esse desenvolvimento também do ponto de vista da chegada, o que equivale a dizer que distanciar-se de Feuerbach é aproximar-se de David Ricardo, em que o capital ganha uma gramática própria a partir da teoria do valor-trabalho. Além disso, há no Capital uma junção de Ricardo com uma exposição de tipo hegeliana que permite ir além daquele. Marx não se contenta em investigar o valor de uma perspectiva quantitativa, mas sim busca entender sua forma-valor a partir do trabalho abstrato. Isso será essencial para 
entender não apenas como Marx solucionará a questão, em aberto desde suas formulações iniciais, de saber de que modo o universal se efetiva concretamente, mas sobretudo para compreender como o próprio Giannotti, ancorando-se nessa solução, desenvolverá sua própria dialética da sociabilidade: trata-se de adotar um procedimento metodológico diferente daquele a que recorreu o jovem Marx, o qual carecia ainda de um estatuto "científico" para pensar o concreto das relações sociais e oferecer uma análise (e uma crítica) imanente do processo de produção, valorização e distribuição do capital.

O acesso ao modo como o capital funda em si mesmo sua substância social está na teoria do valor-trabalho. Não obstante Marx abstrair a materialidade das mercadorias ao considerá-las como valor de troca - pois, a despeito da variedade das mercadorias em seu aspecto útil, o valor pressupõe uma identidade que abstrai seus valores de uso, assegurando simultaneamente a função social da troca -, tal abstração é objetiva porque determina sua substância social. Além disso, o valor estabelece um padrão ou medida de acordo com os quais são possíveis todas as atividades concernentes ao modo de produção capitalista: produção, distribuição, troca, consumo etc. Entendemos o valor como medida se o aplicamos aos processos que compõem as ações sociais e, com isso, o vemos estabelecer as condições de reposição do sistema, uma vez que o valor é reposto e aumentado como capital. "É precisamente essa identidade pressuposta, que se repõe por meio dos seus últimos outros, esse relacionamento do mesmo com a diferença, na qual se instaura a trama do valor, que Ricardo e sua escola ignoram" 22.

Porque as diferentes mercadorias podem ser trocadas de forma equivalente entre si, Giannotti acredita poder interpretar o valor como uma regra a partir da qual a igualdade operada na troca é medida. Mas não é só isso. Percebe também que a igualdade presente nas diferentes mercadorias está sendo efetivada em ações que são submetidas a tal regra. Em artigo recente, Giannotti oferece uma formulação clara: "O valor, portanto, é regra a ser seguida pelo entrosamento dos atos individuais de trabalho, os quais unicamente confirmam a medida pressuposta por cada um ao chegar ao fim do processo" 23 . É preciso descrever então como o sentido da medida do valor se efetua por meio de um processo social em que os atos individuais de trabalho repõem a medida pressuposta. Mas essa medida não está fora do processo que a pressupõe. Pelo contrário, Giannotti mostra que a medida se põe por meio de processos práticos, ou melhor, que a regra a ser seguida está intimamente vinculada às suas condições de efetivação. Trata-se justamente de mostrar "como o trabalho, na qualidade de esquema operatório, onde se imbricam homens e coisas, instaura formas de sociabilidade capazes de se mediarem a si mesmas, de relacionar-se com seus próprios conteúdos"24. E aqui só podemos apontar para uma
[22] Giannotti, J. A. Trabalho e reflexão: Ensaios para uma dialética da sociabilidade. São Paulo: Brasiliense, 1983, p. 226.

[23] Giannotti, J. A. "A perda do mundo". Novos Estudos, 82, 2008 , p. 82 .

[24] Giannotti, J. A. Trabalho e reflexão, op. cit., p. 60. 
[25] Cf. Habermas, J. “Arbeit und Interaktion". In: Technik und Wissenschaftals 'Ideologie'. Frankfurt/M: Suhrkamp, 1967.

[26] Giannotti, J. A. Trabalho e refle$x \tilde{a} o$, op. cit., p. 20.

[27] Ibidem, p. 10. trama que será investigada de forma impressionante em seu livro de maior fôlego, Trabalho e reflexão, de 1983. Vale lembrar que, ao entender o processo de trabalho como "reflexão operosa", estão em causa não somente aspectos instrumentais eestratégicos do trabalho. Giannotti se recusa a entender a racionalidade presente no trabalho segundo os termos de uma "razão instrumental" e também a separá-la, como o fez Jürgen Habermas, da "interação" social25: "Nada mais enganoso do que separar radicalmente, por um corte originário, o comportamento orientado por fins determinados, um agir técnico vinculado ao trabalho, e o comportamento comunicativo, interação entre os homens mediatizada por regras" ${ }^{26}$. O trabalho já representaria em seu movimento de reflexão uma forma social não limitada à técnica, mas sim uma relação socialmente reflexiva.

Trabalho e reflexão não pode ser lido como um texto de história da filosofia. É antes um estudo de ontologia social que cumpre parte central daquela investigação sobre o sentido objetivo da ação social iniciada indiretamente em seu livro anterior. Parece se unificar aqui algo que nas Origens da dialética do trabalho foi abordado da perspectiva da história da filosofia: se no livro de 1966 é exposto o percurso que levou Marx, em sua teoria madura, a desvendar as formas elementares da sociedade capitalista, em 1983 interessa a Giannotti justamente o "próprio processo de presentificação do capital contemporâneo" 27 . Giannotti pode manter-se fiel, mesmo lançando mão de um novo vocabulário filosófico, às intenções do Marx maduro de compreender, com a teoria do valor-trabalho, a sociabilidade capitalista. Mas "manter-se fiel" a Marx significa agora ter de criticar os limites da gênese categorial apresentada no Capital. Como tornar isso compatível com o que há de mais vivo em seu pensamento? Giannotti percebe que a própria racionalidade imanente ao capitalismo, construída pelas categorias do valor, do capital e do lucro, toma uma direção que colocaria em xeque a força das análises imanentes de Marx. Sem recorrer a qualquer pressuposto que não a medida do valor, o trabalho operava de modo a emprestar sentido e necessidade às relações sociais. Ao se generalizar a substância social do valor, que se repõe constantemente no processo de trabalho, o sistema econômico acaba extrapolando sua própria estrutura e, com isso, a identidade mesma do sistema entraria em contradição, o que equivale a dizer que o valor perderia sua força de medida. Giannotti não retira dessa contradição interna do sistema os elementos de sua superação. Verifica antes que a perda de medida do valor anuncia um desafio teórico e prático para aqueles que possuem somente as categorias reconstruídas por Marx, uma vez que o processo produtivo passa a não mais repor os elementos que o efetivam. E se o capitalismo se transforma, mas perversamente permanece, cabe continuar a 
analisá-lo criticamente no seu modo de operar. Não éessa a lição que os ensinamentos de Marx poderiam nos legar?

No final de Trabalho e reflexão é explicitada a tentativa de "refletir como o desenvolvimento tecnológico afeta a própria constituição do valor, na sua qualidade de representação coletiva e meio de socialização do trabalho" 28 . A análise do funcionamento do capital apresentada ali mostra que o trabalho "logo se integra materialmente num organismo produtivo cujos parâmetros de produtividade se dispersam em diferentes níveis, substituindo-se o antigo papel aglutinador do capital social total pelo capital estatal, agora chave da abóboda de todo o sistema" 29 . Se as análises acompanham metodologicamente Marx no que diz respeito a ter de compreender os diversos fatores que influenciam a realização do capital, a referência serve apenas para contrastar com as categorias oferecidas por aquele, pois o que se verifica é justamente a subversão da medida pelo movimento então considerado. De qualquer modo, conceitos ali presentes, como o de "esquema operatório", ausente no próprio Marx, deveriam servir para dar continuidade às investigações de Giannotti sobre os procedimentos do capitalismo contemporâneo. "No esforço de enfrentaresses desafios", afirma Giannotti em entrevista, "Wittgenstein foi de toda valia. Não visei simplesmente colocar Marx na nova moda [...] Ora, se, em Trabalho e reflexão, eu já tinha elaborado a noção de esquemas operatórios, Wittgenstein me permitiu jogaressa noção para o plano da linguagem, da expressão, e entender a relação de troca como uma forma de pensamento, um juízo prático se exprimindo no intermediário dinheiro" 30 . Cabe perguntar também se fez sentido trazer Wittgenstein para a elaboração posterior de suas análises e ainda conseguir, como pretendeu Giannotti, manter as mesmas preocupações metodológicas de uma análise imanente da gramática do capital.

Evidentemente que também são diferentes as consequências práticas desse novo diagnóstico. A contradição entre capital e trabalho gerida pelo capitalismo abriria uma possibilidade imanente de superação política do sistema: a revolução. Não se trata de afirmar a inexistência atual da contradição entre capital e trabalho, mas de perceber que hoje essa contradição já não levaria a uma solução política logicamente intrínseca ao processo no qual ela se constitui. Giannotti não entende que a análise da racionalidade do capital a partir de suas contradições internas permite de fato uma previsão de seu movimento futuro. $O$ preço a pagar por esse resquício hegeliano seria voltar a operar segundo um "misticismo lógico" sempre criticado pelo próprio Marx.

Giannotti sabe, porém, que não se deve confundir a elaboração de programas sobre o futuro com o gesto de apontar as possibilidades inscritas no presente. Uma justificação teoricamente adequada de tal gesto implica sublinhar que "uma nova forma só pode surgir respei-
[28] Ibidem, p.347.

[29] Ibidem, p. 360.

[30] Entrevista de J. A. Giannotti em Nobre, Marcos e Rêgo, José M. (orgs.). Conversas com filósofos brasileiros. São Paulo: Editora 34, 2000, p. 103. 
[31] Ibidem, p.371.

[32] Ibidem, p. 372 .

[33] Cf. Giannotti, J. A. Certa herança marxista, op. cit., pp. 175 ss.

[34] Ibidem, pp. 314-15.

[35] Ibidem, p. 184. tando os termos em que a contradição capital-trabalho se manifesta hoje" ${ }^{31}$. No capitalismo tardio se institui a possibilidade de um corpo político em que os indivíduos, enquanto proprietários de sua força de trabalho, consigam "assegurar suas condições de existência como governantes do sistema produtivo" ${ }^{32}$. Não é apenas com o fim do capitalismo, portanto, que se supera a contradição específica do capital. Em Trabalho e reflexão são os elementos disponíveis efetivados no sistema presente, ou seja, num capital perverso porque infinito, os únicos que permitem ancorar as possibilidades imanentes da "revolução dos nossos dias". Esse diagnóstico surpreendentemente estranho não só ao marxismo, mas também a Marx, não mantém seu ponto de vista metodológico atrelado àquele do próprio Marx? Aquela insistênciaem compreender rigorosamente os procedimentos metodológicos empregados por Marx não adviria desse esforço de conhecer as formas elementares atuais da sociabilidade capitalista? O que parece permanecer nesses diagnósticos tão distantes é a exigência epistemológica de considerar os termos efetivos em que a contradição se coloca.

Em livro mais recente, Certa herança marxista, nota-se mais claramente o movimento que leva as análises categoriais de Marx a confluírem agora para a ideia de uma contradição travada 33 . Os termos continuam sendo aqueles de uma crítica imanente da gramática das relações de trabalho que compõe o modo de produção capitalista. E a consideração de Marx como um clássico que deve ser corretamente compreendido aparece explicitamente atrelada à necessidade de criticar as formas de racionalidade do capitalismo contemporâneo: fazê-lo via Marx não é senão um "desvio" necessário. "Na tradição hegeliana e marxista", diz Giannotti, "creio ser possível indagar pela racionalidade do capital a partir de suas contradições internas, explorando o espaço aberto entre o que sua intenção promete como forma de sociabilidade contratual e o que resulta das ações consideradas corretas e incorretas"34. Não obstante reaparecer aqui sua tese anterior quanto à impossibilidade de estender a gênese categorial para o novo capitalismo, é em Certa herança marxista que Giannotti sublinha as implicações da passagem da "contrariedade" para a "contradição" e explicita os limites do desdobramento das análises formais efetivas da gramática do capital: porque a medida do valor está comprometida com a diversidade da produtividade do trabalho, valor e trabalho agora já não permitem ver como a medida poderia ser reposta e estabelecer um padrão homogêneo para todas as atividades produtivas 35 . Sai de cena, entretanto, um capital dependente da administração do Estado para dar lugar à dinâmica explosiva dos mercados nacionais e internacionais.

Essa tentativa de retirar dos próprios processos sociais possibilidades efetivas de mudança implica repensar o modelo de crítica imanente apresentado no Capital em razão da nova configuração política e econô- 
mica do capitalismo atual. Giannotti não acreditava ser possível haver uma necessidade interna de superação produzida a partir da contradição entre capital e trabalho sem que passássemos da questão social para a questão política, arena na qual teríamos de pensar a manifestação atual da referida contradição e entrever certas práticas políticas vinculadas ao novo funcionamento do capitalismo. Porém, o que aconteceria se aquela capacidade de gerir o sistema produtivo vislumbrada em Trabalho e reflexão já não respondesse hoje à questão de saber como combinar o planejamento econômico com a dinâmica do mercado? É mais difícil compreender a partir de Certa herança marxista como as aberturas práticas e políticas se justificam, uma vez que o estudo das estruturas atuais do modo de produção capitalista nos levaria a "aceitar a contradição travada do capital sem o empuxo interno da superação" 36 .

Se não estamos apenas diante de uma recepção de Marx contra o marxismo, mas em grande parte de Marx contra ele mesmo, por que insistir, ante uma gama considerável de autores contemporâneos que se debruçam sobre a compreensão do presente, em tomá-lo como referência, superior às demais, da crítica da racionalidade de um capitalismo que não é mais o mesmo? Parece claro que a dúvida de Giannotti quanto à visão marxista da política atinge a tese de uma contradição entre capital e trabalho que engendra a superação do capitalismo pelo proletariado. Uma forma de luta política que já não encontra as condições socioeconômicas para se reproduzir - sobretudo porque o marxismo sempre dependeu do trabalhador total - esgarça o vínculo cobrado por Giannotti entre o possível e o real. Nesse caso,éa política que precisa inventar novas maneiras de tratar a contradição do capital37. Ou, como afirmou recentemente, "se a questãoé política,então façamos política. Mas eficaz, que tome como ponto de partida as condições dos sistemas políticos atuais, e examinemos teórica e praticamente suas possibilidades de mudança" 38 . Não seríamos forçados, no entanto, a pensar a questão da política tendo como referência apenas aquilo que hoje faltaria nos textos de Marx, pois estes se distanciariam das novas formas de sociabilidade em curso? Como fortalecer a herança crítica de Marx à racionalidade do capital sem pressupor encontrar novamente as contradições econômicas que sustentavam a dinâmica da política? Se tivermos de ir hoje aos textos de Marx para compreender aspectos decisivos de nossa contemporaneidade, o que seus textos nos diriam sobre outras formas de dominação que não aquelas vinculadas às relações de classe socioeconômicas, ou outras formas de interação política que não relações hierárquicas de poder, ou outras críticas à sociedade capitalista que não se fundam apenas na dialética do trabalho?

RÚRION MELO é professor de teoria política do departamento de ciências sociais da Unifesp e pesquisador do Cebrap.
[36] Ibidem, p. 332

[37] Cf. Giannotti, J. A. "Socialismo ou barbárie". Folha de S. Paulo, 25/03/2001.

[38] Giannotti, J. A. Marx além do marxismo, op. cit., p. 8.

\begin{tabular}{l}
\hline Recebido para publicação \\
em 21 de junho de 2011. \\
\hline NOVOS ESTUDOS \\
CEBRAP \\
90, julho 2011 \\
pp. $21-32$ \\
\hline
\end{tabular}

